\title{
The Existentialist's Survival Guide. How To Live Authentically in an Inauthentic Age, Gordon Marino
}

Matías Tapia Wende

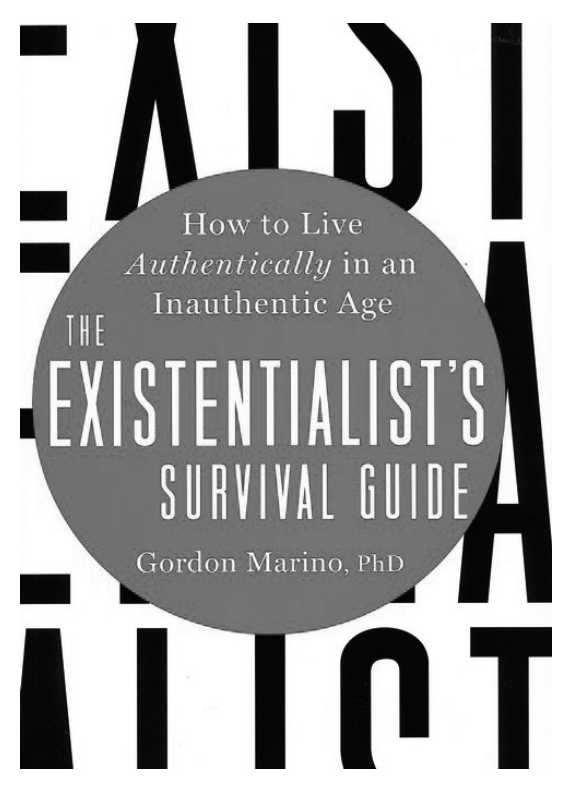

Gordon Marino, The Existentialist's Survival Guide. How to Live Authentically in an Inauthentic Age. San Francisco: HarperOne, 2018. 260 pp.
En el artículo "Why Philosophy?”, el filósofo estadounidense Ken Taylor sostiene que hay una tensión entre el virtuosismo conceptual desarrollado por aquellos que se dedican a la filosofía y la posibilidad de comunicar al público general los hallazgos de este, más o menos estructurado, afán comprensivo. Un intento por salvar esta brecha lo encontramos en The Existentialist's Survival Guide, del compatriota de Taylor, Gordon Marino, entrenador de boxeo, doctor en Filosofía por la Universidad de Chicago y actualmente director de la Hong Kierkegaard Library en Minnesota, Estados Unidos. Marino, quien cuenta con varios esfuerzos recopilatorios e introductorios, concentrados en publicaciones 
como Kierkegaard in the Present Age, The Cambridge Companion To Kierkegaard y Basic Writings of Existentialism and Ethics: The Essential Writings, se propone en esta ocasión "articular las visiones constructivas de los existencialistas"', no desde una perspectiva desapegada o puramente abstracta, sino a partir de una apropiación genuina y vital de las ideas base del existencialismo. Marino asume una visión de la filosofía en tanto búsqueda de una “comprensión preteorética de cómo vivir" y despliega, en consonancia, una reflexión en clave existencialista —en una modulación de pensamiento en primera persona y desde adentro hacia fuera- sobre diversos aspectos del proceso vital.

Además de una introducción y un epílogo, el libro cuenta con siete capítulos, divididos en dos grupos: aquellos que refieren a emociones o condiciones desafiantes de la vida (angustia, depresión y desesperación, y muerte) $\mathrm{y}$ aquellos que apuntan a dimensiones más positivas, aunque a veces igualmente complejas (autenticidad, fe, moralidad y amor). En cada uno de estos acápites, el autor entrega las lecciones que con los años ha extraído de pensadores como Søren Kierkegaard, Fiódor Dostoievski, León Tolstoi, Arthur Schopenhauer, Friedrich Nietzsche, Martin Heidegger, Jean-Paul Sartre, Albert Camus, entre otros. Más allá de las diferencias entre estos autores, cuestión que dificulta dar con una definición y una catalogación certera del gremio de los existencialistas, Marino enfatiza la apuesta, ejecutada por cada uno de ellos, de detenerse a examinar con ayuda de la razón dimensiones de la vida que tradicionalmente habían quedado relegadas por su irracionalidad. Recuperar estas meditaciones, dice Marino, es importante en una época tan revuelta en cuanto al bienestar de la subjetividad como la que nos toca enfrentar.

De la mano de Kierkegaard, Heidegger y Freud, este último fuera de 
los límites del existencialismo, Marino defiende que la angustia no es una mera enfermedad, sino que representa la "manifestación de nuestra naturaleza espiritual". ${ }^{2}$ Esta constitución radical debe asumirse en los alcances que tiene respecto a la realización de la libertad y en consecuencia de la responsabilidad que el individuo toma de sí mismo y sus relaciones con otros. En la misma línea, en lo que toca a la depresión y la desesperación, Marino exhorta a alejarse del fisicalismo. En efecto, determinados desbalances químicos pueden producir inestabilidad en los estados de ánimo de una persona, pero no agotan la profundidad que puede tener tal o cual disposición afectiva. Recuperando una distinción kierkegaardiana, Marino muestra que la depresión puede entenderse como un desorden sicológico, mientras que la desesperación alcanza el rango de desorden espiritual. Lejos de pretender dibujar el cuadro de una vida perfecta y feliz como paradigma de sanidad mental y existencial, Marino postula, con Kierkegaard, que somos responsables de la manera en que nos relacionamos con nuestras emociones y sentimientos, y de la forma como nos arreglamos con la conciencia de lo que nos ocurre: la depresión deviene desesperación "cuando nos dejamos definir por nuestra depresión y, en nuestra desesperanza, tiramos la toalla en cuanto a nuestras aspiraciones morales y espirituales". ${ }^{3}$ Hacia el final de esta porción referente a los desafíos abiertamente negativos de la existencia, Marino aborda la muerte, echando mano de Kierkegaard, Tolstoi, Camus y Heidegger. Llama a considerar la riqueza aleccionadora de la muerte percibida por estos autores, ya sea a través de la práctica filosófica o de la creación literaria. Pensar en la muerte e incluso "pensarse a sí mismo en la muerte", ${ }^{4}$ de acuerdo con Marino, nos reconfigura para la vida.

El problema de la autenticidad inicia la segunda parte del libro. Marino reconoce la dificultad que entraña definir lo auténtico, más cuando corren 
tiempos en los que la deshumanización y la impersonalidad son piedras de toque. Sin asentarse en disponer la subjetividad auténtica sólo en la concordancia entre sentir y ser, y enfatizando la importancia del carácter de constructo humano que tiene esta categoría, Marino bosqueja la autenticidad, con Kierkegaard, Camus, Nietzsche y Heidegger, en tanto que es un cierto modo de unificación apasionada y consciente de nuestras ideas. Esta composición debe conservar en todo momento una impronta moral. 5 El autor discute sobre la posibilidad efectiva de articular un aparato de sentido existencial en torno al ejercicio de la fe. Al contrastar la visión crítica de Camus, con la fe como una aniquilación intelectual, y la concepción de Kierkegaard, donde la fe opera un cambio paradójico y radical en el creyente, Marino se las arregla para desarrollar aspectos confesionales y seculares dirigidos a relevar la importancia de ordenar nuestras creencias y practicar la confianza. ${ }^{6}$ Llegado este pun- to, el autor se apresta a debatir sobre la moralidad, denominador común en sus articulaciones previas sobre la conciencia y la acción en el sujeto. En la mayor muestra de consistencia a lo largo de todo el texto, Marino delinea, de la mano de Sartre, Nietzsche y del omnipresente Kierkegaard, una batería de nociones sobre lo moral, reunida con lo adquirido por medio de su experiencia como entrenador de boxeo: lo central es tener el coraje de hacer frente a situaciones que ponen en juego el valor real de las verdades en las que decimos vivir. ${ }^{7}$

Finalmente, Marino encalla en el amor, la clave de resolución que vincula la autocomprensión y el volcamiento hacia los otros. A partir de la pregunta de cómo dar, encontrar y recibir amor, y con el reconocimiento de que, en términos positivos, los existencialistas no serían la primera fuente para defender la capitalidad de lo amoroso, Marino destaca algunas aristas significativas de Sartre, Camus, Dostoievski y Kierkegaard. El amor, 
describe Marino, envuelve el conocimiento de uno mismo y la aceptación de nuestras condiciones, al tiempo que se confirma en una apertura a recibir a los demás en su propia condición; al ejecutar una idealización desmedida y destructora, "queremos ser amados como las personas que queremos ser o que tal vez imaginamos que somos, no como las falibles criaturas de carne y hueso que somos". ${ }^{8}$

En el epílogo, que hace las veces también de conclusión, Marino resalta: lo que ha venido desarrollando no es un manual exacto para una vida más feliz, sino precisamente una guía de supervivencia para navegar por la ingente y nunca acabada tarea de existir. Marino sostiene que, para afrontar una época que socava la capacidad de los individuos para hacerse cargo de sí mismos, al adormecer la conciencia y saturar los cuerpos con soluciones pasajeras y farmacéuticas, hay que proveerle un lugar a lo irracional. Aunque por momentos pareciera que machaca sobremanera las bondades del cristianismo y de la fe cristiana, Marino refuerza que hay una cierta perspectiva secular desde la cual podemos mirar nuestra tarea espiritual. Pensar nuestra subjetividad como un descubrimiento o una creación, se presenta al fin y al cabo, como "un salto de fe gigante".?

El lector encontrará en The Existentialist's Survival Guide una serie de conceptos filosóficos, al servicio de una comprensión llana y una apropiación existencial de aquello que se construye en la teoría. Tal vez no haya marca más distintiva de la filosofía que su emergencia en una cierta apertura emocional, esto la determina en su inicio y la gobierna en su despliegue. Al llegar lejos en la consideración de las oscuridades del universo, el ser humano no ha dado con misterio más abundante que el que habita en él mismo. Marino nos comparte las herramientas que el existencialismo le ha proveído para no sucumbir a ese desafío compartido por todas y todos. ${ }^{10}$

Marino, The Existentialist's, 222.

Marino, The Existentialist's, 241.

Se está preparando una versión en español de The Existentialist's Survival Guide, a través de la editorial de la Universidad Iberoamericana, Ciudad de México. Esta edición contará con un prefacio especial preparado por Gordon Marino. 


\section{Referencias}

Taylor, Ken. "Why Philosophy?". Philosopher. 26 de agosto de 2016. https:// politicalphilosopher.net/2016/08/26/featured-philosopher-ken-taylor/. Fecha de consulta: 12 de agosto de 2019. 